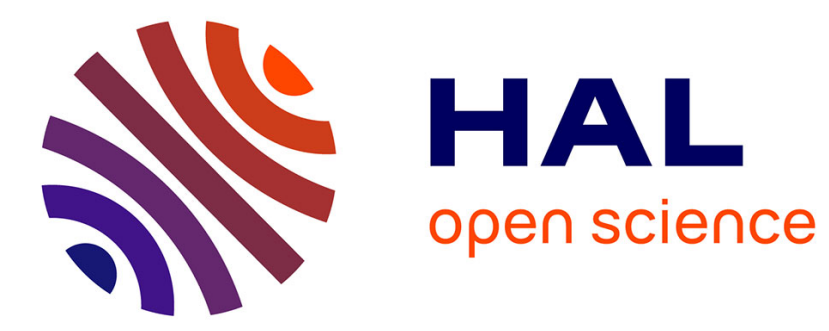

\title{
Modelling regional land change scenarios to assess land abandonment and reforestation dynamics in the Pyrenees (France)
}

Laure Vacquié, Thomas Houet, Terry L. Sohl, Ryan Reker, Kristi L Sayler

\section{- To cite this version:}

Laure Vacquié, Thomas Houet, Terry L. Sohl, Ryan Reker, Kristi L Sayler. Modelling regional land change scenarios to assess land abandonment and reforestation dynamics in the Pyrenees (France). Journal of Mountain Science, 2015, 12 (4), pp.905-920. 10.1007/s11629-014-3405-6 . hal-01194834

\section{HAL Id: hal-01194834 \\ https://hal-univ-tlse2.archives-ouvertes.fr/hal-01194834}

Submitted on 8 Sep 2015

HAL is a multi-disciplinary open access archive for the deposit and dissemination of scientific research documents, whether they are published or not. The documents may come from teaching and research institutions in France or abroad, or from public or private research centers.
L'archive ouverte pluridisciplinaire HAL, est destinée au dépôt et à la diffusion de documents scientifiques de niveau recherche, publiés ou non, émanant des établissements d'enseignement et de recherche français ou étrangers, des laboratoires publics ou privés. 


\title{
Modelling Regional Land Change Scenarios to Assess Land Abandonment and Reforestation Dynamics in the Pyrenees (France)
}

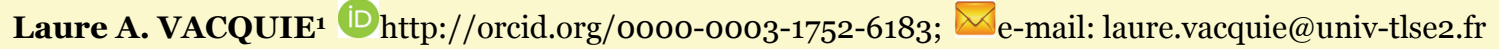 \\ Thomas HOUET1 iD http://orcid.org/oooo-0oo1-5890-6145; e-mail: thomas.houet@univ-tlse2.fr \\ Terry L. SOHL² iD http://orcid.org/oooo-ooo2-9771-4231; e-mail: sohl@usgs.gov \\ Ryan REKER3 iDhttp:// orcid.org/oooo-0oo1-7524-0082; e-mail: rreker@usgs.gov \\ Kristi L. SAYLER² iD http://orcid.org/oooo-0oo3-2514-242X; e-mail: sayler@usgs.gov \\ 1 GEODE Laboratory, Toulouse Jean Jaurès University, 5 alleys Antonio Machado, 31000 Toulouse, France \\ 2 U.S. Geological Survey, Earth Resources Observation and Science (EROS) Center, Sioux Falls, SD 57198, USA \\ 3 ASRC Federal - InuTeq, Contractor to U.S. Geological Survey, Earth Resources Observation and Science (EROS) \\ Center, Sioux Falls, SD 57198, USA
}

Citation: Vacquie LA, Houet T, Sohl TL (2015) Modelling regional land change scenarios to assess land abandonment and
reforestation dynamics in the Pyrenees (France). Journal of Mountain Science 12(4). DOI: 10.1007/s11629-014-3405-6

(C) Science Press and Institute of Mountain Hazards and Environment, CAS and Springer-Verlag Berlin Heidelberg 2015

\begin{abstract}
Over the last decades and centuries, European mountain landscapes have experienced substantial transformations. Natural and anthropogenic LULC changes (land use and land cover changes), especially agro-pastoral activities, have directly influenced the spatial organization and composition of European mountain landscapes. For the past sixty years, natural reforestation has been occurring due to a decline in both agricultural production activities and rural population. Stakeholders, to better anticipate future changes, need spatially and temporally explicit models to identify areas at risk of land change and possible abandonment. This paper presents an integrated approach combining forecasting scenarios and a LULC changes simulation model to assess where LULC changes may occur in the Pyrenees Mountains, based on historical LULC trends and a range of future socio-economic drivers. The proposed methodology
\end{abstract}

Received: 5 December 2014

Accepted: 26 March 2015 considers local specificities of the Pyrenean valleys, sub-regional climate and topographical properties, and regional economic policies. Results indicate that some regions are projected to face strong abandonment, regardless of the scenario conditions. Overall, high rates of change are associated with administrative regions where land productivity is highly dependent on socio-economic drivers and climatic and environmental conditions limit intensive (agricultural and/or pastoral) production and profitability. The combination of the results for the four scenarios allows assessments of where encroachment (e.g. colonization by shrublands) and reforestation are the most probable. This assessment intends to provide insight into the potential future development of the Pyrenees to help identify areas that are the most sensitive to change and to guide decision makers to help their management decisions.

Keywords: Pyrenees; Land use change; Land cover change; Land abandonment; Mountain landscape; 
Reforestation; LULC Model

\section{Introduction}

Land use and land cover (LULC) change processes are an important part of global environmental changes affecting biodiversity, climate and environmental services (UNEP 2002; Lambin et al. 2006). In Europe, land use is dominated by agriculture and forestry which covers $45 \%$ and $36 \%$ of the EU-25 states, respectively (FAO 2003), with 34\% of terrestrial area used for crop production and $14 \%$ for grassland (Verburg et al. 2006a). For centuries, agriculture has shaped a variety of landscapes across Europe as the result of various management strategies and policies, local human decision-making and physical factors.

In the last century, LULC of European mountains has experienced substantial transformations. Supporting competitive agriculture, the Common Agricultural Policy (CAP) has favored intensification and specialization of agriculture production neglecting less favored areas such as mountain lands (ACAP 2011). Moreover, constant modifications of regulations and management policies (e.g. CAP reforms, regulation measures for consumer and environment protection, quotas for food production, incentives for specific land management) have caused rapid changes in agricultural practices influencing land management. Concurrently, the decreasing number of agricultural employees and aging of farmers have led to agropastoral land abandonment and fewer farm holdings (Mottet et al. 2006). The socio-ecological and cultural richness of mountainous regions relies on an anthropogenic heritage, where landscapes were built and maintained by farmers and foresters. Thus, agropastoral and logging activities have historically played a key role in shaping and maintaining mountain landscapes (Mitchley 2006). The critical situation affecting agricultural sectors, combined with the recent introduction of competing activities (e.g. tourism, recreation activities), have raised major concerns for politicians, planners and local stakeholders (Busch 2006) dealing with mountain land use.
Over the next decades, many European regions will face major demographic, economic and technological modifications (Renwick et al. 2013). Many studies have proposed that rapid changes are to be expected, and predicted a massive decrease in agricultural areas (Rounsevell et al. 2005; van Meijl et al. 2006) and increase in encroachment (i.e. colonization by shrublands) and spontaneous reforestation on formerly open-lands (Garbarino et al. 2014). Such dynamics have been predominant in the French Pyrenees Mountain over the past 60 years and are expected to intensify at the expense of agro-pastoral lands in the upcoming decades (Métailié and Paegelow 2004; Galop et al. 2013).

However, LULC changes (Land Use and land Cover Change) processes in the Pyrenees are complex, occurring at various temporal and spatial scales, with interlinked environmental, societal and economic impacts (Houet et al. 2012; Grandjean et al. 2013). The extents of these changes are difficult to predict as are their impact on the environment, landscapes and rural societies. The uncertainties in future landscape evolution lie in the fact that they result from driving factors occurring at various spatial scales, affecting current and future landscape organization at different levels of intensity (Turner II et al. 1995).

Scenarios, representing a variety of potential future outcomes, have become popular tools in a number of research projects to inform spatially and temporally explicit models assessing LULC changes. Starting from a known initial situation and exploring the future to illustrate feasible trends of evolution, scenarios can help to understand the complexity of driving factors and distinguish their respective and combined effects on landscape evolution (Verburg et al. 2006b; Houet et al. 2010).

Scenario exercises exist at the global level and focus on the impact of anthropogenic activities on natural resources (IPCC 2000; UNEP 2002; MEA 2005). Using global drivers of change (e.g. demographic changes, economic growth and technological development) they describe alternative futures of the world for impact, adaptation and vulnerability assessments (Alcamo et al. 2006). However, because they are conducted at coarse spatial and temporal scales, they fail to provide insights into the consequences of changes at the landscape level. Concurrently, several 
European projects focus on rural development and agricultural policies by downscaling quantitative indicators of change from a global extent to a spatial and temporal scale that is relevant for regional assessment studies (Klijn et al. 2005; Rounsevell et al. 2005; Verburg et al. 2006a). While investigating the impacts of economic trends and global climate/land-use changes on the potential vulnerability of Europe's ecosystems, such case studies remain limited for finer scale assessment (e.g. small regions or landscape) since most processes affecting global and regional changes are the consequences of locals dynamics and policies (Veldkamp and Lambin 2001; Houghton 2003). Since these drivers are hard to comprehend and to model at larger scales, many local assessments have been developed over the years among various research themes (Gibon et al. 2010; Bourgoin and Castella 2011; Marohn et al. 2013). These local assessments, primarily involving participatory approaches with local stakeholders, are usually centered on driving factors and policies representative of the studied area but do not depict processes and their impact at the regional level. Finally, even if a large number of studies have addressed the issue of LULC changes in Europe combining scenarios and LULC changes models, few have focused specifically on European mountains at a regional scale (Schneeberger et al. 2007; Zimmermann et al. 2010; Price et al. 2015).

The objective of this paper is to characterize areas potentially affected by land abandonment in the future for the Pyrenees Mountains. We use a LULC change model accounting for landscape patterns to allocate the expected LUCC change for four contrasting scenarios. They are developed in order to account for past trends using LUCC analyses and regional specificities that have been already considered in existing sectorial narratives. Moreover, because conventional LUCC data (Corine Land Cover) underestimates observed changes occurring at finer scale (Verburg et al. 2006a), all these data are empirically used to refine future sub-regional LUCC changes. We hypothesize that using multiple scenarios will help to refine the identification of areas at stake for local and regional decision makers.

\section{Materials and Methods}

\subsection{Study area}

The French Pyrenees covers 18,00o $\mathrm{km}^{2}$ and includes three regions (i.e. regional administrative organizational level): the Aquitaine, the MidiPyrenees and the Languedoc Roussillon (Figure 1). The climate varies regionally and ranges from oceanic humid (Aquitaine), continental humid (Midi-Pyrenees), Mediterranean dry (LanguedocRoussillon), and mountainous (greater than 2000 $m$ a.s.l.) climate. Because of its geographic position, orientation and geological structure, the Pyrenees

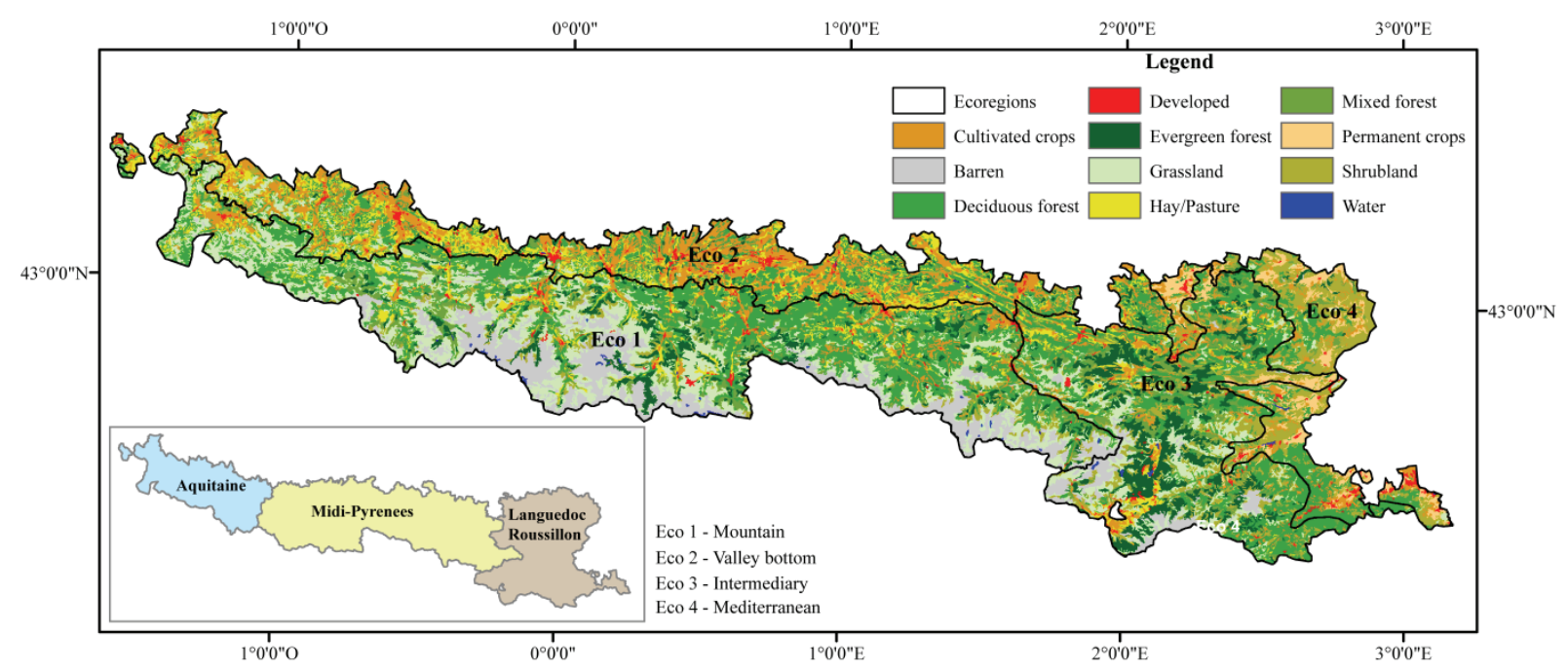

Figure 1 Land use and land cover map from 2006 (Corine Land Cover 2006) with ecoregions of the French Pyrenees. The study area is represented by three administrative regions (Aquitaine, Midi-Pyrenees and LanguedocRoussillon). 


\begin{tabular}{lllll} 
Table 1 Ecoregions main characteristics & & & \\
Ecoregions & Climate & Elevation & Mean annual temp. & Precipitation \\
\hline Mountain & Mountain & $65-3210 \mathrm{~m}$ & $7-13^{\circ} \mathrm{C}$ & $900-2000 \mathrm{~mm}$ \\
Valley bottom & Oceanic/Mountain & $5-940 \mathrm{~m}$ & $8-13^{\circ} \mathrm{C}$ & $900-1500 \mathrm{~mm}$ \\
Intermediary & Mountain/Mediterranean & $70-2900 \mathrm{~m}$ & $8-12^{\circ} \mathrm{C}$ & $640-1000 \mathrm{~mm}$ \\
Mediterranean & Mediterranean & $0-1060 \mathrm{~m}$ & $12-15^{\circ} \mathrm{C}$ & $500-1000 \mathrm{~mm}$
\end{tabular}

consist of contrasting ecological regions with variations in temperatures and an increase of precipitation positively correlated with the elevation.

Based on similar biogeographic factors (e.g. climate, geology, physiography), four homogeneous ecological regions are delineated by the French National Forest Inventory agency: the "Mountain" (Eco 1), "Valley bottom" (Eco 2), "Intermediary" (Eco 3) and "Mediterranean" (Eco 4). They each represent specific bioclimatic conditions for the survival and development of natural species and are used to assess past and future LULC changes (Table 1).

\subsection{LULC-change model}

A wide variety of spatially explicit LULCchange models have been developed over the past two decades. Literature reviews are available and offer an overview on the use of modeling tools and their assets for prospective studies (Verburg et al. 2004). For this study, the forecasting scenarios of land-use change (FORE-SCE) model (Sohl and Sayler 2008) is used for two main reasons: (1) it can deal with regional and sub-regional LULC dynamics (land demand) influenced by socioeconomic drivers and (2) it can mimic observed landscape patterns detected from the analysis of LULC maps by uploading landscape metrics. It is assumed that landscape change patterns remain stable over time and the use of patch characteristics from observed LULC changes does not affect the validity of the outputs. Moreover, it has been widely used in the conterminous United States to spatially allocate LULC changes for various assessment studies (Sleeter et al. 2012; Sohl et al. 2012; Sohl et al. 2014).

The FORE-SCE model uses distinct "demand" and "spatial allocation" modules to partition the modeling of future land-use proportions (demand module) and the mapped location of future landuse change (spatial allocation module). Demand can be provided by a variety of sources, including extrapolations of historical changes, economic models, quantitative scenario construction, or any other framework that provides regional-scale landuse proportions. The spatial allocation module uses suitability surfaces to guide where future landscape change occurs. Using a wide range of known drivers of LULC changes (e.g. topography, slope, climate, soil data) (Appendix 1), logistic regression is used to construct suitability-of-occurrence maps for each LULC type. It was used here to simulate LULC changes at 5-years intervals for the period 2006-2100. A patch-based allocation procedure is used to place change on the landscape (guided by the suitability surfaces) until the demand for each LULC type is reached. If there are no more possibilities for a given LULC class to be allocated (i.e. the demand cannot be respected), the FORESCE model stops allocating this particular class. Patch characteristics (e.g. mean and standard deviation for patch size) are derived from historical LULC data and are calculated in FRAGSTATS (McGarigal et al. 2002) to represent typical patch size distribution of each LULC type across the landscape and sub-regions. FORE-SCE model structure and function is extensively described in Sohl et al. (2008, 2014).

\subsection{Scenario development and LULC modelling}

This study intends to present possible future LULC changes under specific socio-ecological conditions using the combination of land-use scenarios and a LULC changes model. The methodological approach was initially based on the one proposed by Houet et al. (2010): (1) identifying past LULC trends (2) model calibration and validation, (3) developing scenarios and (4) modeling LULC change processes. It allows integrating data at multiple spatial and temporal scales, and taking into account all drivers affecting land-use change, while maintaining a manageable level of model complexity (Sohl et al. 2010). However, due to the lack of appropriate input 
spatial data, this method was adapted. The scenarios (storylines) were firstly defined through the combination of existing reports focusing on future land uses over the study area. The method used is presented in section 1.3.1 and the storylines in section 1.3.2. Then, because the LULC changes provided by regional land cover maps are strongly under-estimated for two ecoregions compared to those observed at finer scales, future land changes were empirically modified and adapted accordingly to the storylines (section 1.3.3).

\subsubsection{Defining the scenarios: methodology}

The methodological approach for constructing the scenarios was based on existing storylines (i.e. qualitative and participatory assessment of alternate futures) made by regional and national institutions which have been adapted and downscaled for the various sub-regions. Since numerous studies have been developed by various national research communities over the last 20 years, there was a need to evaluate which ones were relevant and could serve as a basis for our scenarios. Four criteria were used to select and review existing sets of scenarios.

(1) Scenarios should fall within a global approach since global and regional scenarios represent large scale driving factors on LULCchanges. Global variables are usually used as a context for land-use changes at finer scales by defining and constraining socio-ecological conditions (Alcamo et al. 2006). This global context should include information regarding economic growth, energy cost and assumptions on world trade policies, since they are key driving forces for the Pyrenees production system;

(2) Regarding French development, the scenarios should contain national policies and management leanings, e.g. environmental and urbanization legislations, CAP orientations and public policies (financial support for agriculture activities, and market interventions);

(3) The scenarios need to include local knowledge - through a participatory approach since it provides a more detailed representation of LULC-changes by linking them to specific human decision-making and local physical factors;

(4) The scenarios have to present an exhaustive storyline regarding agricultural activities and have to assess forestry management strategies to estimate their impacts on LULC dynamics since they are the dominant land use types.

Among the six reports that were considered, four were selected as they provided information regarding at least one of the criteria mentioned above (Table 2). It appeared none of the above scenarios, considered independently, contained all the elements required to develop storylines that are believable, consistent and relevant to the actual environmental/socio-economic trends and policies for the Pyrenees as each serve a specific purpose in terms of agricultural, forestry and socio-economic analysis. However, elements of each scenario could be combined to fill thematic gaps and provide exhaustive storylines for the Pyrenees system. The Vert et al. (2013) scenarios offered the best starting point for its overall thematic veracity and its time frame. Additional elements from the three remaining reports (e.g. specific CAP orientations or forestry management strategies, quantitative projections given for example in Vert and Portet (2013), etc.) were integrated to fulfill each scenario of the Vert et al. (2013) report as long as they were relevant to the initial storyline. A summary of each report, illustrating their respective contribution to the definition of the storylines is given in Appendix 2. Thus, the scenarios developed are grounded on predefined storylines, each of which was then expanded based on additional information while making sure that they matched the initial scenario's thematic scope.

\begin{tabular}{|c|c|c|c|c|c|}
\hline Studies & $\begin{array}{l}\text { Global } \\
\text { context }\end{array}$ & $\begin{array}{l}\text { National policies } \\
\text { and management } \\
\text { strategies }\end{array}$ & $\begin{array}{l}\text { Participator } \\
\text { y approach }\end{array}$ & $\begin{array}{l}\text { Rich details about } \\
\text { agricultural } \\
\text { activities }\end{array}$ & $\begin{array}{l}\text { Forestry } \\
\text { management } \\
\text { strategies }\end{array}$ \\
\hline Vert et al. (2013) & ++ & + & ++ & ++ & + \\
\hline Vert and Portet (2010) & ++ & + & + & + & O \\
\hline CGAAER (2010) & + & ++ & + & $\bigcirc$ & - \\
\hline Bourgau et al. (2008) & ++ & + & 0 & + & ++ \\
\hline
\end{tabular}

Notes: (++) Very high; (+) High; (O) Moderate; (-) Limited. 


\subsubsection{Scenario storylines}

Four contrasting scenarios were developed and differentiated by their means of adaptation to different trajectories of socio-economic development and environmental disturbances (Figure 2). The means of adaptation translates the desire of the French government to support rural and/or logging production by applying particular public policies. Each storyline intends to emphasize a specific socio-economic paradigm which could influence land use changes in a major way.

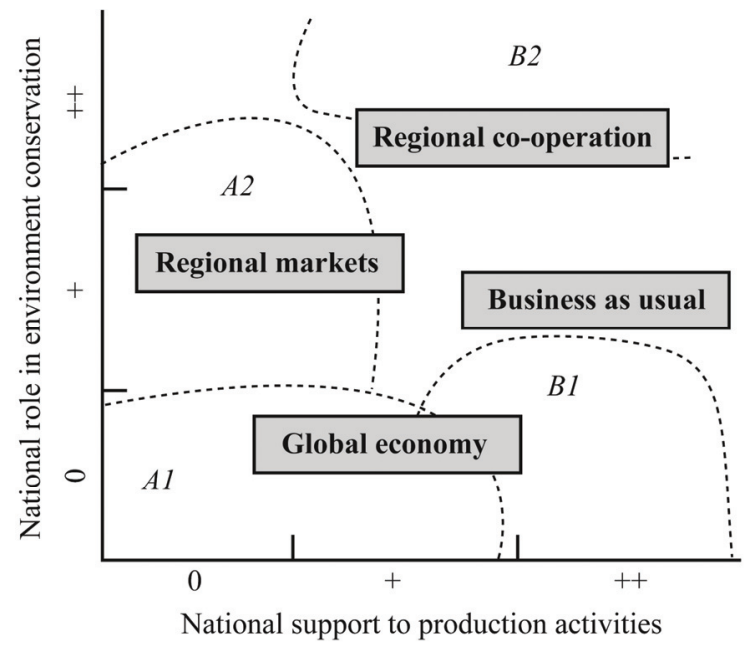

Figure 2 Socio-economic orientations prevailing in each of the scenarios and their position within the IPCC SRES scenarios framework.

\section{Business as usual}

This scenario is built on the assumption that there are no major changes in terms of global economy, public policy and land management. The CAP organization remains unchanged and offers the same financial supports to subsidize agricultural production in mountainous terrain. Current LULC trends observed for the recent past will continue into the future. Even if this scenario appears less realistic by avoiding an expected reform of the CAP, it provides a reference to which other scenarios can be compared.

\section{Global economy}

This scenario fits into a context of high economic growth and a liberalization of international trade. Economic development is a priority and environmental and rural issues are neglected by both national managers and society. The CAP is reformed and a drastic reduction of agricultural financial aid causes the bankruptcy of many farms which strongly depend on policy-based agricultural support payments. To meet the global demand in goods and energy needs, the agroforestry sectors focus on production in higher quality production areas (e.g. accessible and profitable lands). Difficult lands to access in less favored areas are expected to be less intensively used and are assumed to be abandoned and reforested.

\section{Regional markets}

This scenario expects a major reconstruction of the agricultural sector under the influence of consistently high prices of fossil fuels and a reduction in international trade. Agricultural costs (e.g. fuel and fertilizers) are expected to increase, affecting farmers' profitability and as a result, prices for agricultural commodities. In the absence of national political interventions and high agricultural production costs, public policies are primarily implemented by regional authorities. This new autonomy leads the regions to implement contrasting management strategies to reinforce their own policies. The CAP is regionalized while the European Union, in a joint effort with the regions, favors local measures in terms of establishing plans to mitigate agricultural expenses.

\section{Regional co-operation}

This scenario is oriented toward a strong political and societal concern regarding energy, climate and environmental issues. Ambitious conservation policies are implemented at the European level. In response to the environmental requirements, the CAP architecture is modified to reduce the environmental impact of agricultural activities while optimizing production rates. CAP financial support policy is based on the quantity and quality of environmental services provided. There is a strong environmental consensus and a significant rallying of farmers, consumers and public authorities to support environmental conservation. A major energy and environmental transition is observed in the agroforestry sector to optimize land conservation.

\subsubsection{Data and magnitude of future LULC changes}

This study used the 2006 Corine Land Cover (CLC) data (CEC 2007) resampled to $125 \mathrm{~m}$ 
resolution as the starting land cover for the future scenario projections. Producing accurate, reliable and timely LULC mapping at a fine spatial resolution and a large spatial extend still remains a challenge for the global change community (Giri et al. 2013). Although there is ongoing work to map and characterize LULC in the Pyrenees (Ducrot et al. 2014), there are no historical LULC maps available providing a continuous record of LULC changes at the regional scale; CLC data remain the only usable database for this study. We used 1990 and 2006 CLC data to establish the initial demand for the "Business as usual" scenario. However, because of its spatial and temporal resolution, CLC data do not properly reflect landscape evolution trends (Verburg et al. 2006a) and underestimate LULC changes (Appendix 3), raising doubts of the validity of LULC change rates extracted from statistical analysis (Santini and Valentini 2011). To compensate for this effect and better characterize LULC trends, the annual demand of LULC changes was corrected for the mountain and intermediary ecoregions where LULC changes reach only $\pm 6 \%$ of change based on the CLC database while they exhibit stronger rates at finer scale. To do so, we use results from a local research LULC change assessment: the MODE RESPYR project (Houet et al. 2012; http://w3.mode-respyr.univ-tlse2.fr/ index.php). This project provided historical and statistical information on contemporary (19402000) LULC changes (e.g. gross, net, conversions) for three Pyrenean valleys (Sheeren et al. 2012; Vacquie et al. 2013). Based on this knowledge, change rates identified through CLC data between 1990 and 2006 were weighted by local trends observed over the past 60 years. It is assumed that LULC trends observed locally are representative of LULC changes in these ecoregions and these finding corroborate the LULC dynamics observed elsewhere in the Pyrenees (Cohen et al. 2011). Based on identified change rates, a LULC changes matrix was defined for the "Business as usual" scenario. Through an empirical approach based on expert knowledge, this scenario projects an overall decrease of agricultural land ( $-13 \%$ for crops, $-6 \%$ for hay/pasture) and grassland (-20\%) in all ecoregions (except for crops in valley bottom) compensated for by increasing forest $(+20 \%)$ and shrublands $(+14 \%)$.

For each of the "Global economy", "Regional markets" and "Regional co-operation" scenarios, the quantity of change to be allocated corresponds to a proportional increase or decrease of measured change rates of the "Business as usual" matrix, balanced by socio-economic and/or bio-climatic conditions (Table $3 \mathrm{a}-\mathrm{d}$ ). In the "Global economy"

Table 3 Demand for each scenario by ecoregions and LULC classes (in $\pm \% / y e a r)$. Bold figures reflect the overall increase or decrease of the demand for the entire area. Forest includes deciduous, evergreen, and mixed forest classes; Dev. stands for developed.

\begin{tabular}{llclllll} 
Scenario & Crops & Hay, pasture & Grass & Forest & Shrub & Dev. & Water, barren \\
\hline (a) Business as usual & -13 & -6 & -20 & 20 & 14 & 6 & -1 \\
Mountain ecoregion & -6 & -11 & -29 & 43 & 3 & 1 & -1 \\
Valley bottom ecoregion & -23 & 15 & -14 & -1 & 10 & 12 & 0 \\
Intermediary ecoregion & -3 & -26 & -13 & 37 & 5 & 1 & -1 \\
Mediterranean ecoregion & -21 & -1 & -23 & 2 & 37 & 9 & -2 \\
(b) Global economy & -13 & -6 & -20 & 20 & 14 & 6 & -1 \\
Mountain ecoregion & -6 & -11 & -29 & 43 & 3 & 1 & -1 \\
Valley bottom ecoregion & -23 & 15 & -14 & -1 & 10 & 12 & 0 \\
Intermediary ecoregion & -3 & -26 & -13 & 37 & 5 & 1 & -1 \\
Mediterranean ecoregion & -21 & -1 & -23 & 2 & 37 & 9 & -2 \\
(c) Regional markets & -10 & -6 & -19 & 18 & 14 & 5 & -2 \\
Mountain ecoregion & -2 & -8 & -28 & 31 & 10 & 2 & -5 \\
Valley bottom ecoregion & -23 & 15 & -14 & -1 & 10 & 12 & 0 \\
Intermediary ecoregion & 0 & -21 & -15 & 26 & 11 & 1 & -2 \\
Mediterranean ecoregion & -15 & -9 & -20 & 13 & 26 & 6 & -2 \\
(d) Regional co-operation & 10 & 0 & -4 & -2 & 1 & 2 & -8 \\
Mountain ecoregion & 10 & 2 & -2 & 5 & 5 & 1 & -21 \\
Valley bottom ecoregion & 5 & 14 & -10 & -9 & -4 & 5 & 0 \\
Intermediary ecoregion & 15 & -12 & 5 & 0 & -3 & 1 & -6 \\
Mediterranean ecoregion & 11 & -3 & -9 & -4 & 7 & 3 & -4 \\
\hline
\end{tabular}


scenario, Vert and Portet (2010) find that given the economic difficulties farmers are facing, livestock are expect to decrease by $17 \%$ with a concurrent decrease of hay and pasture lands (i.e. between $-3 \%$ and $-5 \%)$. Grasslands are following similar trends and are expected to decrease by $22 \%$. Assuming a $\pm 2 \%$ margin, this scenario presents the same magnitude of change as the "Business as usual" scenario. However, additional reports assume a more intensive use of high quality production areas, submitting Less Favored Areas (LFAs) and precarious lands across the Pyrenees to more intensive changes. Thus, this scenario uses the same LULC change matrix as the "Business as usual" scenario but with a different spatial allocation of LULC changes. In the "Regional markets" scenario, Vert and Portet (2010) predict an overall decrease of hay/pastures (i.e. -6\%) and crops in low lands (i.e. -23\% in the valley bottom ecoregion) with associated impacts on the rest of the demand. Moreover, in a context where local political solutions are implemented to maintain the economic and environmental integrity of the Pyrenees, the magnitude of change is weighted by a longitudinal gradient favoring LULC changes in the Languedoc-Roussillon since the region is less agriculturally productive, and more sensitive to socio-economic and environmental changes. The "Regional co-operation" scenario presents relatively small changes due to policy assumptions that maintain agricultural production. According to Vert and Portet (2010), declines in agricultural and grassland areas are expected to be less in this scenario. They predict a stability of livestock which leads to a stability of hay/pasture lands and a $2 \%$ decrease of grasslands. Since grass land cover prevails in the mountain ecoregion, this decrease was favored in this ecoregion. Concurrently, a slow increase of crop yields is expected which translates into a $5 \%$ increase of crop lands in the valley bottom ecoregion. The increase of developed areas and decrease of water and barren land cover remain low compared to the magnitude of change in other LULC classes in all scenarios. Such contrasted scenarios, whether it is in terms of quantity of LULC change and/or in terms of spatial allocation, are expected to provide insights into a scope of potential futures of the Pyrenees Mountains and to help identify areas at stake, i.e. potentially concerned by land abandonment.

\subsection{Scenarios' comparison and assessment}

Initial assessment of scenario results consists of comparing the allocation of LULC across scenarios. Results are compared between scenarios and administrative regions (i.e. Aquitaine, Midi-Pyrenees and Languedoc-Roussillon) which are more relevant to assess LULC changes in regard to specific socioeconomic conditions. Since land abandonment dynamics is of importance in mountainous areas, the assessment of area at stake is made by overlaying the four scenarios. The resulting map highlights future uncertainty according to contrasted scenarios, i.e. where LULC changes inland abandonment is occurring in one or several scenarios (Verburg et al. 2010). Because land abandonment is made of encroachment and reforestation, a refined mapping approach is proposed. It is assumed that a pixel exhibiting encroachment in one scenario and reforestation in another scenario has a higher probability of being abandoned than a pixel with only encroachment or reforestation. In the same way, a pixel exhibiting reforestation and encroachment in two different scenarios has a lower probability of being abandoned than a pixel exhibiting reforestation in one scenario and encroachment in three scenarios since reforestation is expected to overcome encroachment.

\section{Results}

\subsection{Comparison of the scenarios at the region administrative scale}

The interaction between the demand for agricultural lands, forest, grassland/shrubland, spatial policies and land requirements results in highly variable land use dynamics across scenarios. Table 4 shows the percentage of land that is projected to change in each of the scenarios and indicates which part of the Pyrenees is expected to face the most change in LULC between 2006 and 2100. Due to the high rates of change observed in the past 60 years, the "Business as usual" scenario is the most dynamic with $24 \%$ of the total land area changing from one land use type to another. Of all thematic scenarios, the "Regional market" scenario presents the highest rates of landscape change resulting in an overall change of $18 \%$ of the total 
study area followed by the "Global economy" with the conversion of $14 \%$ of the total area while only $8 \%$ of the Pyrenees are predicted to change under the "Regional co-operation" scenario. Regionally, high rates of change are typically associated with regions where land productivity is highly dependent on socio-economic drivers and where climatic and environmental conditions limit intensive production and profitability (e.g. conversion of $11 \%$ to $26 \%$ of the total area of the Languedoc-Roussillon region). Conversely, low rates of change are common in regions with high adaptability rates to socio-economic and climatic changes and where land resources are used at their highest intensity (e.g. conversion of $9 \%$ to $11 \%$ of the total area of the Aquitaine region).

\subsection{Assessing land abandonment and reforestation dynamics}

Of all changes in land cover, reforestation is the most important in term of net change (Figure 3 ). The largest amount of change is a net gain of $2.432 \mathrm{~km}^{2}$ in the "Business as usual" scenario which equals an overall increase of forest of approximately 35\%. The "Regional markets" and "Global economy" scenarios project a net forest gain of $1.850 \mathrm{~km}^{2}(+25 \%)$ and $1.478 \mathrm{~km}^{2}(+20 \%)$, respectively. Accounting for the largest portion of the landscape in 2006, covering approximately $41 \%$ of the total land area, the increase of forest lands has a significant impact on landscape patterns. For the "Regional markets", "Global economy" and
"Business as usual" scenarios, it is between 9\% and $14 \%$ of the total area of the Pyrenees that is expected to change due to reforestation alone and between $11 \%$ and $20 \%$ because of landscape enclosure (i.e. abandoned agricultural areas including those colonized by shrub and forest) (Table 5).

Land abandonment is the primary cause of this trend. Agro-pastoral land use and land cover (e.g. agriculture, hay/pasture and grasslands) have an overall net loss in the "Business as usual", "Regional markets" and "Regional co-operation" scenarios equivalent to respective losses of 2.725 $\mathrm{km}^{2}, 1.723 \mathrm{~km}^{2}$ and $1.480 \mathrm{~km}^{2}$. Amongst those different LULC types, grasslands - used as summer pastures in high elevation areas - consistently change by the largest amount with a decrease ranging from $1.121 \mathrm{~km}^{2}$ to $1.682 \mathrm{~km}^{2}$ (-31\% to $\left.-64 \%\right)$ depending upon scenario (Figure 4). On the whole, land abandonment counter balances reforestation dynamics and is directly responsible for the modification of $10 \%$ to $18 \%$ of the Pyrenean landscape (Table 5). As a consequence of incentives to maintain agricultural production, some agricultural areas expand in the "Regional cooperation" scenario leading to a reduction of forest and shrub land cover. The agricultural landscape remains stable with only $3.32 \%$ of the Pyrenees expected to change due to land abandonment and $1.20 \%$ due to reforestation (Table 5). A pattern of interest is the slight increase of hay/pasture in the Aquitaine region in all scenarios except for the "Business as usual". This overall stability of

\begin{tabular}{lllll}
\multicolumn{2}{l}{ Table 4 Total area changed due to land use change across the Pyrenees for the different scenarios } \\
\cline { 2 - 5 } Scenario & \multicolumn{5}{c}{$\begin{array}{l}\text { \% of land area changed between } \\
\text { 20o6 and 210o }\end{array}$} \\
\cline { 2 - 5 } & $\begin{array}{l}\text { Entire } \\
\text { Pyrenees }\end{array}$ & $\begin{array}{l}\text { Aquitaine } \\
\text { region }\end{array}$ & $\begin{array}{l}\text { Midi-Pyrenees } \\
\text { region }\end{array}$ & $\begin{array}{l}\text { Languedoc-Roussillon } \\
\text { region }\end{array}$ \\
\hline Regional markets & 18.59 & 11.09 & 16.50 & 26.35 \\
Global economy & 14.68 & 11.42 & 12.49 & 19.91 \\
Regional co-operation & 8.46 & 9.01 & 6.29 & 11.29 \\
Business as usual & 24.37 & 25.86 & 22.20 & 26.59
\end{tabular}

\begin{tabular}{|c|c|c|c|c|}
\hline Landuse types & Regional markets & Global economy & $\begin{array}{l}\text { Regional } \\
\text { co-operation }\end{array}$ & Business as usual \\
\hline Land abandonmenta & 12.08 & 10.08 & $3 \cdot 32$ & 17.76 \\
\hline Landscape enclosureb & 14.97 & 11.69 & 2.98 & 19.83 \\
\hline Reforestation & 10.71 & 8.88 & 1.20 & 14.26 \\
\hline
\end{tabular}

Notes: a This includes abandoned agricultural lands, e.g. crops, hay/pastures and grasslands colonized by shrubland or forest; ${ }^{\mathrm{b}}$ This includes any areas colonized by shrubland or forest. 

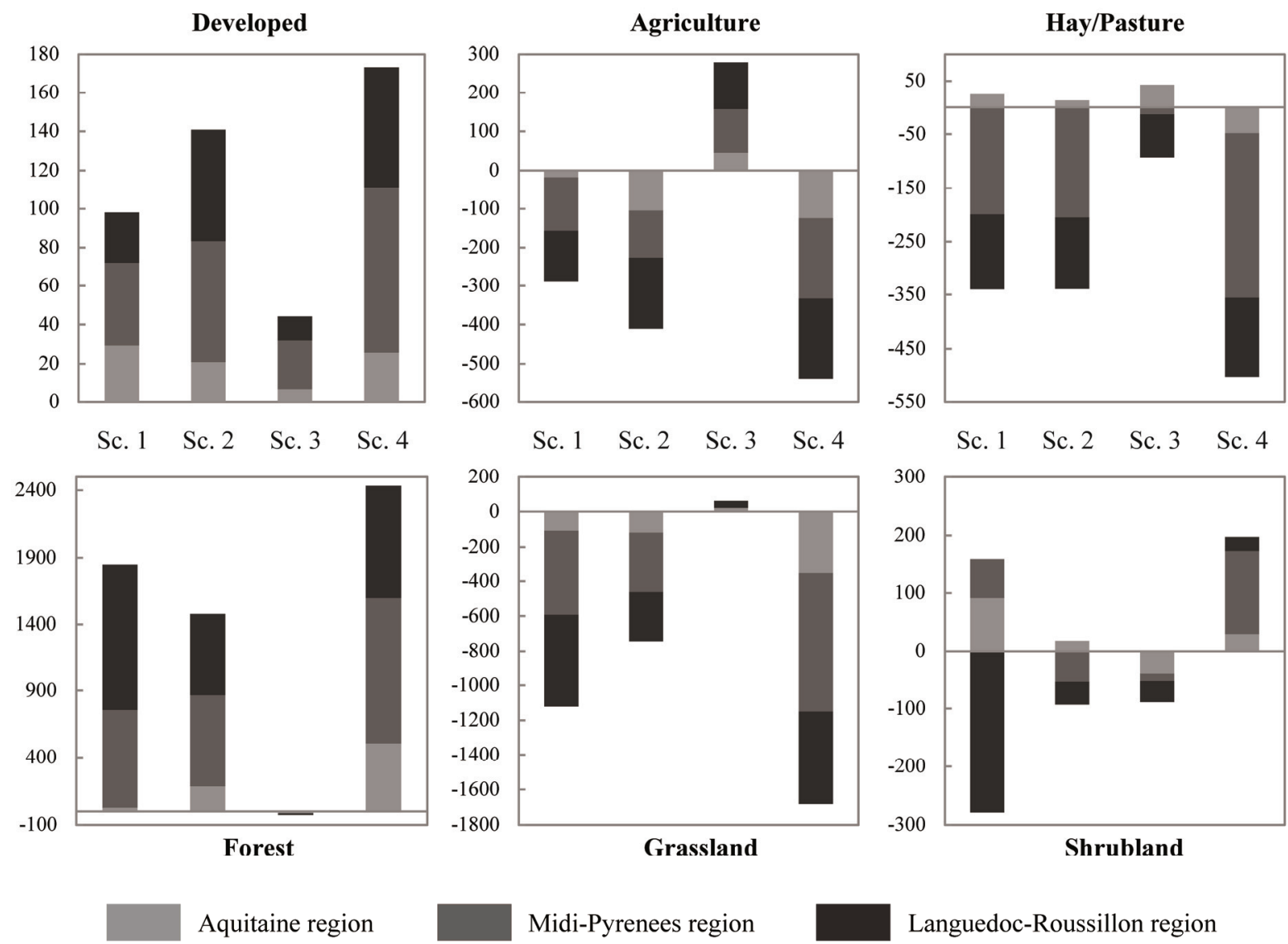

Grassland

Shrubland

Languedoc-Roussillon region

Figure 3 Projected net change in each of the 3 regions of the Pyrenees between 2006 and 2100 for each of the major land use (top row) and land cover (bottom). The vertical axis is in $\mathrm{km}^{2}$. Scenario 1 is "Regional market", scenario 2 is "Global economy", scenario 3 is "Regional co-operation" and scenario 4 is "Business as usual". Agriculture includes cultivated crops and permanent crops classes. Forest includes deciduous, evergreen and mixed forest classes.

pasturelands is consistent with the current and predicted dynamics of this region maintaining high pressure on available land resources.

Agricultural areas most sensitive to land abandonment and reforestation dynamics are typically found in LFAs and administrative regions with low production rates. Figure 4 a shows that large parts of the agro-pastoral landscape are completely unaffected by future LULC change especially in the valley bottom and in the Aquitaine region where land abandonment dynamics remain low and scattered across the landscape. Although there are differences between allocations of LULC change between scenarios, some areas are projected to face abandonment, regardless of the scenario conditions, especially in the far eastern portion of the Midi-Pyrenees and in the Intermediary and Mediterranean ecoregions, e.g. areas with low production efficiency and low level of adaptability to socio-economic and environmental changes. Moreover, the characterization of abandonment in terms of landuse and land-cover replacement can be used to identify alternate processes, e.g. encroachment versus reforestation dynamics. Areas that have the highest probability to be subjected to reforestation dynamics are mainly found at the geographic limits of existing forest areas in the Mountain ecoregion (Figure 4b) and to a lesser extent in the lower zones of the Intermediary and Mediterranean ecoregions (Figure 4c). Concurrently, encroachment dynamics are identified in the valley bottom and in the highest elevation slopes (e.g. above the tree line) where agro-pastoral lands have a higher probability to evolve into shrublands given the bio-climatic conditions. Climatic conditions are also relevant for the Mediterranean ecoregion where high temperatures and dry summers are more suitable for the development of shrublands (Figure 4c).

The spatial allocation of land abandonment in 
relation to topography (i.e. elevation and slope) is also useful to identify the most sensitive areas to LULC changes. Figure 5a shows the proportion of pixels presenting a high probability of being abandoned (i.e. occurring in 3 of the 4 scenarios Figure $4 \mathrm{~b}$ and $4 \mathrm{c}$ ) for 50 meters altitude intervals. Values for each region are normalized by their respective area to make them comparable. Overall, the lower slopes of the Aquitaine region (i.e. 500$600 \mathrm{~m}$ a.s.l.) appear to be the most vulnerable to land abandonment, similarly to the Midi-Pyrenees and Languedoc-Roussillon (i.e. 500-900 $\mathrm{m}$ a.s.l. and $900-1100 \mathrm{~m}$ a.s.l. respectively). In the latter region, the peak between $1500 \mathrm{~m}$ a.s.l. and $1660 \mathrm{~m}$ a.s.l. is representative of the LULC changes that have been occurring in the uplands (i.e. mountain summer pasture) abandoned since the 1950 s and presenting a high probability for encroachment and reforestation with an upward shift of forest, also spreading at lower elevations (i.e. 900-1100 m

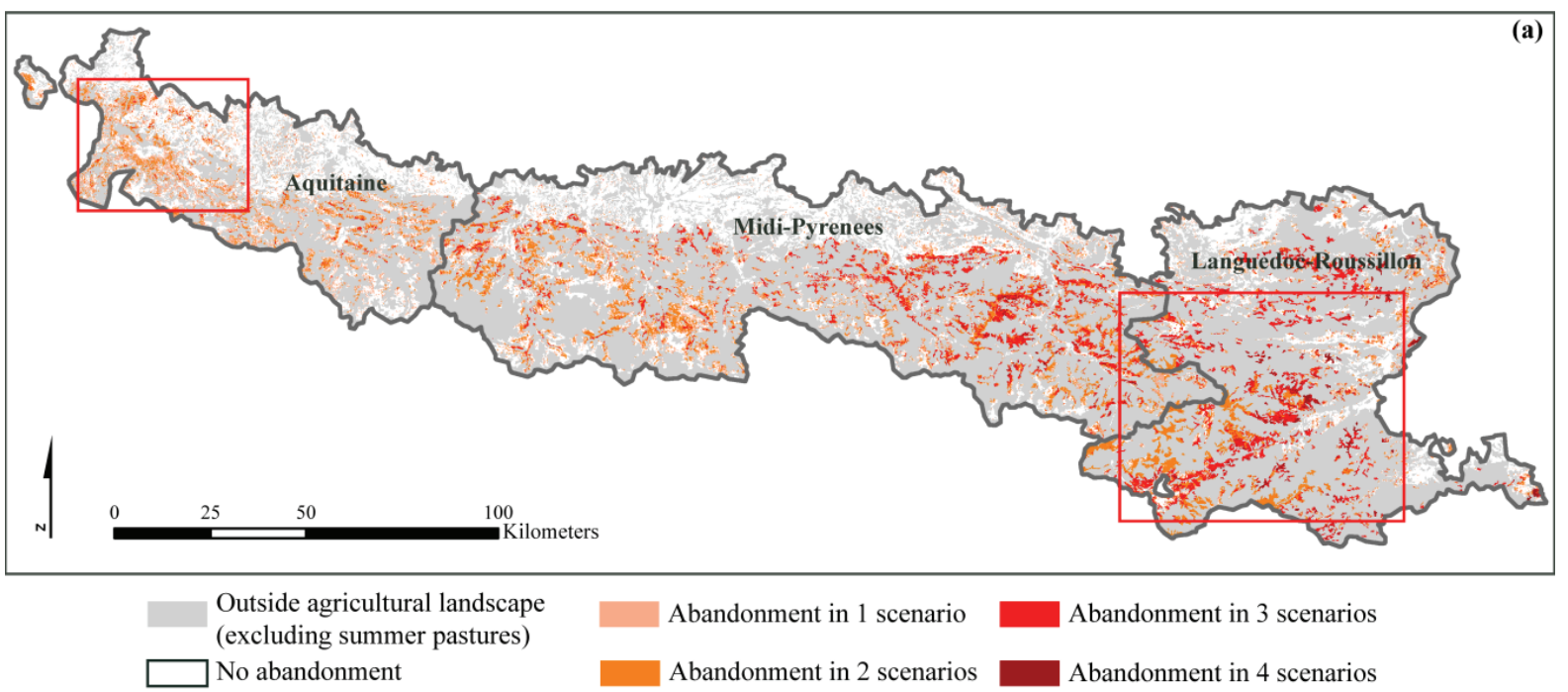

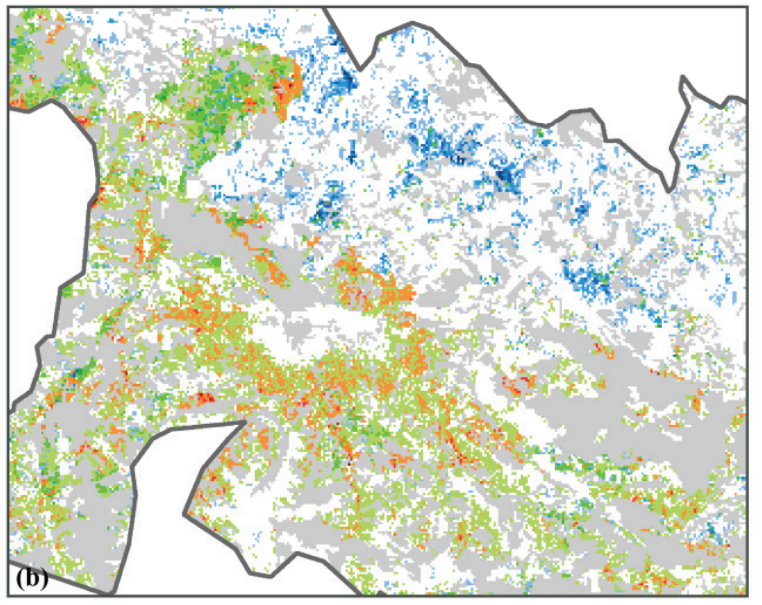

Outside agricultural landscape (excluding summer pastures) No abandonment

Encroachment (1 scenario)

Encroachment (2 scenarios)

Encroachment (3 scenarios)

Encroachment (4 scenarios)

Forest (1 scenario)

Forest (1 scenario) / Encroachment (1 scenario)

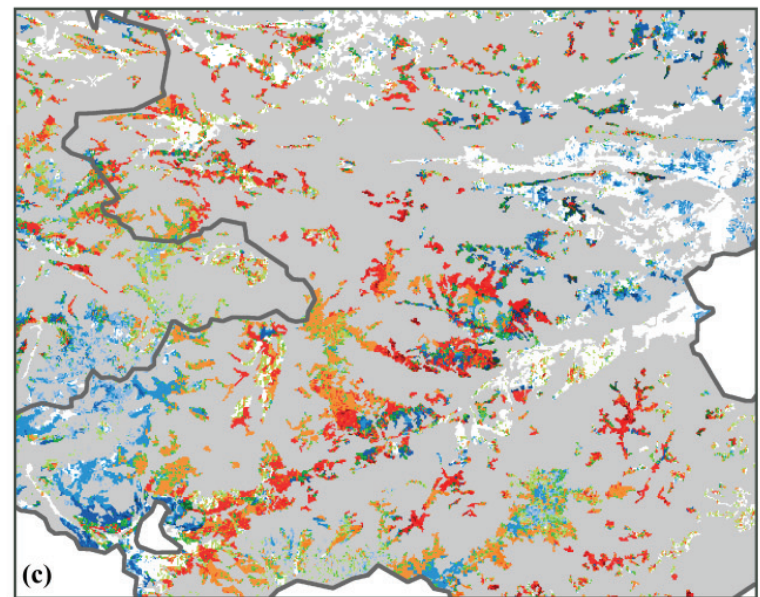

Forest (1 scenario) / Encroachment (2 scenarios)
Forest (1 scenario) / Encroachment (3 scenarios)
Forest (2 scenarios)
Forest (2 scenarios) / Encroachment (1 scenario)
Forest (2 scenarios) / Encroachment (2 scenarios)
Forest ( 3 scenarios)
Forest (3 scenarios) / Encroachment (1 scenario)
Forest (4 scenarios)

Figure 4 Frequency of simulated land abandonment within (a) the agro-pastoral landscape and (b-c) its corresponding LULC conversion at finer spatial scales. 


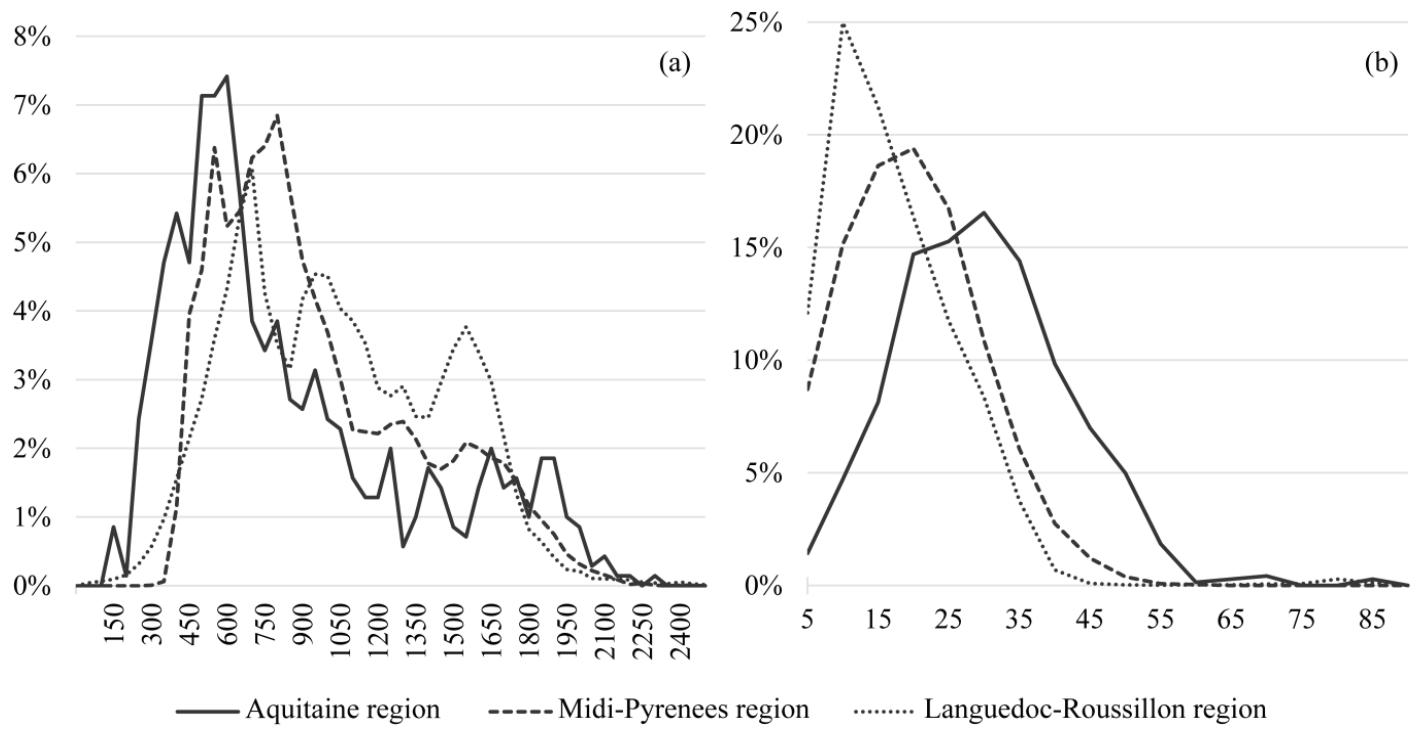

Figure 5 Percentage of pixels presenting a $75 \%$ chance of being subjected to land abandonment based on (a) elevation (in meters) and (b) slope (in degrees) for each region of the Pyrenees Mountain.

a.s.l.). In the Aquitaine and Midi-Pyrenees regions the most vulnerable lands are located in the steepest areas (i.e. 25-30 degrees and 15-20 degrees respectively), while the opposite trend can be observed in the Languedoc-Roussillon region (i.e. lower than 10 degrees) (Figure $5 \mathrm{~b}$ ). This trend can be expected to occur gradually through the west as steepest areas were those primarily reforested in the Languedoc-Roussillon.

\section{Discussion}

\subsection{Relevance of a multi-scale approach for building scenarios and simulating LULC changes}

Houet et al. (2011) stated that it is from a comprehensive and explanatory picture of a complex system that a prospective study (i.e. scenario construction) can be implemented, accounting for interactions of multi-scaled drivers. However, the value of a phenomenon taking place within a specific landscape is generally dictated by causal processes at various spatial scales. Therefore, a clear and precise understanding of the processes occurring at both regional and local scales is essential to understand such complex systems. The current study integrates local knowledge from national assessment reports to refine each scenario during their construction and to reinforce their plausibility and relevance. Information gathered at the local scale is used to explain dynamics at coarser spatial scales to obtain consistent patterns for the Pyrenees. Moreover, by basing the scenarios on pre-existing studies from national assessments and by accounting for regional structuring patterns, the procedure described in this paper has been successful at determining and constraining LULC change conditions at finer spatial scales. Overall, the approach used here comprises integrating the impacts resulting from local dynamics and the outcomes of regional trends. It puts in perspective global phenomenon and more local dynamics related to anthropogenic factors, and strengthens the observations made at different spatial scales by avoiding poor interpretations of LULC changes.

Since LULC change processes depend on the spatial scale considered, it is also essential to take into account the interdependence of spatial scales when quantifying relationships between LULC and their associated processes (Verburg et al. 2006c). Consequently, the spatial resolution of GIS data used to assess LULC changes has a significant influence on their quantification and spatial organization. In a landscape as complex as the Pyrenees, and in mountainous regions in general where driving factors of change are highly dependent on the spatial extent of the studied area considered, it is crucial to identify LULC changes in the most representative way. Many studies of LULC changes in other mountainous regions use 
CLC data to conduct retrospective assessments and LULC evaluations (Verburg et al. 2006a; Santini and Valentini 2011). However, because of their spatial resolution and temporal horizon, they fail to precisely describe the landscape's evolution and correctly measure LULC changes. The unavailability of detailed and timely land classification maps at global and regional scales remains a major constraint for land-change mapping, monitoring, and modeling and calls for further improvements. To overcome this shortcoming, this study used local knowledge (i.e. LULC change observations in local study sites) to increase the relevance of retrospective statistical analysis since it provides a longer temporal horizon and a higher spatial resolution. While the validity of this approach can be argued by raising the question of the representativeness of the local sites compared to the Pyrenees, it does reflect evolution trends in a better way than would have been done without taking into account local knowledge. Moreover, as carried out by Santini and Valentini (2011) in the Italian Alps, the use of ancillary datasets (e.g. topography, socio-economic) is an effective way of compensating the restrictions induced by CLC data. One other way of increasing its validity would be to increase the number of local study sites along the Pyrenees to assess for local disparities as shown by Zimmermann et al. (2010).

\subsection{Characterizing land abandonment dynamics}

The procedure described in this paper has been successful in simulating LULC change in the Pyrenees by downscaling national assessments and integrating local knowledge. The land-use model accounts for spatial and temporal interactions and integrates specific driving factors (e.g. bioclimatic and geomorphological conditions, and socioeconomic assumptions) for different ecoregions and scenarios. Specific LULC change dynamics emerge reflecting how both local management and national landscape drivers affect the landscape in different environmental and socio-economic contexts. The large declines of agro-pastoral lands observed across the Pyrenees are consistent with the ongoing trends observed over the past century in the Pyrenees (Mottet et al. 2006) and in many other mountainous regions across Europe (Prevosto et al. 2003; Price et al. 2015). The results reflect global dynamics linked to national and European demographical and economical evolutions and relate to both natural and anthropogenic factors. Pyrenean production systems are highly dependent on bioclimatic conditions which determine the spatial distribution of livestock and the intensity of farming production - which are directly correlated to the dynamics of land abandonment and landscape enclosure. Consequently, even if similar dynamics (e.g. encroachment and reforestation) are observed across the Pyrenees, LULC change at the local level may differ due to local driving forces of landscape change.

An analysis of the results for the scenarios developed for this study reveals contrasting land abandonment processes. A latitudinal gradient guiding the establishment of either shrublands or forest can be observed along the Pyrenees Mountains. Hypothesis can be made whether it translates bioclimatic conditions (higher elevations not being a limitation in the Languedoc-Roussillon region due to higher temperatures compared to the Aquitaine region) and/or historical practices (abandoned lands in the Languedoc-Roussillon region are located at higher elevations because lands below $700 \mathrm{~m}$ a.s.l. have been abandoned earlier and are already reforested, contrary to the Aquitaine region). Overall, agro-pastoral abandonment is generally located in marginal areas bordering natural land covers. Thus, while the quantities and types of change differ across the Pyrenees, the spatial pattern of encroachment and reforestation follows similar processes and typically occurs at the margin of agro-pastoral land use as an extension of existing shrubland and forest land cover. Such areas are shown to be particularly sensitive to land abandonment in scenarios that project an increase in production efficiency or an overall decrease of agro-pastoral activities. Moreover, by translating the vulnerability of agro-pastoral lands, the characterization of land abandonment dynamics based on morphologic variables allows a finer identification of high stake areas. Overall, the lower slopes appear to be the most vulnerable to LULC changes, while the uplands of the LanguedocRoussillon region also present a high probability of undergoing land abandonment. Concurrently, encroachment and reforestation are more 
predominant on the steepest areas in the Aquitaine and Midi-Pyrenees regions than in the LanguedocRoussillon. This could indicate that bioclimatic conditions are more binding than the accessibility of lands, especially in the Languedoc-Roussillon region, since areas at lower elevations and slopes are the most vulnerable. Such results intend to provide stakeholders with an insight into potential future evolution of the Pyrenees to improve their management and /or protection orientations.

\subsection{Future perspectives}

Although modelling should involve validation and uncertainty assessments of the simulation results, those issues are not addressed in this paper. It should be understood that the model outcomes are not predicting future LULC but are projecting LULC change based on socio-economic assumptions. In this respect, the purpose of model validation would not be to assess the model predictive capabilities but rather to demonstrate its ability to simulate realistic LULC changes. Validation could be a means to assess the uncertainty of the modeling procedure and estimate the level of reliability a user (e.g. modeler, local planner, etc.) can have in the model (Houet et al. 2014). However, a proper validation requires consistent LULC databases. Although the CLC database features changes in LULC between 1990 and 2006, it is not suitable for validation purposes since the LULC changes identified do not properly depict landscape patterns observed at local scales, as mentioned above.

Turley and Ford (2009) argue that uncertainties in simulation models can stem from the data or the model itself. While data validity remains an issue, a comparison of the outputs of simulations in various modeling platforms (e.g. CLUE, LCM, etc...) would contribute to an assessment of the validity and uncertainty of the simulation results, assuming they offer similar model calibrations. Concurrently, a multi-scale model assessment could serve a similar purpose. Downscaling the scenarios and comparing the outputs at different spatial scales would provide a means to identify uncertainty while accounting for specific (local) landscape processes. In the end, both approaches would serve a similar objective by identifying the redundant simulated abandoned areas within various modelling platforms and/or various spatial scales to assess the model validity and reliability. For practical reasons, a multi-model assessment was not performed for this assessment. However, it should be emphasized that while data and model uncertainties certainly play a role in representing future landscape configurations, it is the variation in the scenarios themselves that is designed to capture overall uncertainties about the future.

\section{Conclusion}

The method presented in this paper focuses on the construction of socio-economic scenarios to forecast LULC changes using a spatially explicit model. The combined use of local and regional knowledge increases the relevance of retrospective analysis to simulate future LULC changes. The method results in the development of LULC maps providing insights into a range of alternative futures using a scope of socio-economic and environmental conditions. This analysis highlights the main trajectories of change and helps to identify areas that are most sensitive to change in order to guide decision makers of the concerned administrative region: medium sloped uplands are of concern in Languedoc-Roussillon while steep slopes nearby in the valley-bottom and in the uplands are the areas expected to be abandoned in the Midi-Pyrenees and Aquitaine regions. The assessment of LULC change trajectories reveals how agro-pastoral landscapes are projected to experience encroachment and reforestation dynamics, regardless of the scenarios. Furthermore, this work reveals how landscape enclosure is positively correlated to the degree of adaptability to socio-economic and climatic changes as well as the intensity of production activities. Remaining challenges are the validation of the model results through the implementation of each scenario into different modeling platforms applied at the regional scale or by comparing the model outputs at various spatial scales using different modeling tools.

\section{Acknowledgements}

This work was supported by the MODE 
RESPYR project (ANR 2010 JCJC 1804-O1) founded by the French National Science Agency (ANR). We would like to thank the reviewers for their helpful comments and suggestions on earlier drafts.

\section{References}

ACAP (2011) Strategic study for the future of agropastoral activity in the Pyrenees, Agricultures et Territoires ACAP Pyrénées. Available online at: http://www.agriculturepyrenees.fr (Accessed March 2015) (In French)

Alcamo J, Kok K, Busch G, et al. (2006) Searching for the future of land: scenarios from the local to global scale, In: Lambin EF, Geist HJ (Ed.) Land-Use and Land-Cover Change - Local Processes and Global Impacts, Global Change - The IGBP Series. pp 137-157.

Bourgau M, Bertin M, Lerat JF, et al. (2008) The French forest in 2050-2100, Ministry of agriculture and fisheries. Available online at: http://agriculture.gouv.fr/la-foret-francaise-en2050-2100 (Accessed March 2015) (In French)

Bourgoin J, Castella J-C (2011) "PLUP FICTION": Landscape Simulation for Participatory Land Use Planning in Northern Lao PDR. Mountain Research and Development 31: 78-88. DOI: 10.1659/MRD-JOURNAL-D-10-00129.1

Busch G (2006) Future European agricultural landscapes: What can we learn from existing quantitative land use scenario studies? Agriculture, Ecosystems and Environment 114: 121140. DOI: $10.1016 /$ j.agee.2005.11.007

CEC (2007) CORINE land cover 2006 Technical guide. Office for Official Publications of the European Communities. Available online at: http://www.eea.europa.eu/publications/ technical_report_2007_17 (Accessed March 2015)

CGAAER (2010) Prospective of the European Common Agricultural Policy 2020. Available online at: http:// agriculture.gouv.fr/prospective-pac-2020-politique (Accessed on 20 May 2010) (In French)

Cohen M, Varga D, Vila J, et al. (2011) A multi-scale and multidisciplinary approach to monitor landscape dynamics: a case study in the Catalan pre-Pyrenees (Spain). The Geographic Journal 177: 79-91. DOI: 10.1111/j.1475-4959.2010.00368.x

Ducrot D, Dejoux JF, Kadiri M, et al. (2014) Natural vegetation land cover method in mountain context and wide area with multitemporal satellite images. In 5th Workshop of the EARSeL Special Interest Group on Land Use and Land Cover - Frontiers in Earth Observation for Land System Science, Berlin, Germany, 17-18th March 2014.

European Commission (2006) European Soil Portal - Soil Data and Information Systems. European Commission - Joint Research Centre, Institute for Environment and Sustainability. Available online at: http://eusoils.jrc.ec.europa.eu/ESDB Archive/ESDB_Data_Distribution/ESDB_data.html (Accessed on 12 March 2015)

FAO (2003) Food and Agriculture Organization of the United Nations - Statistics Division. Available online at: http://faostat3.fao.org/home/E (Accessed on 12 March 2015)

Galop D, Rius D, Cugny C, et al. (2013) Long-term Humanenvironment interactions history in the French Pyrenean Mountains inferred from pollen data. In: Lozny L (Ed.) Continuity and Change in Cultural Adaptation to Mountain Environments. Springer-Verlag, New-York, USA. pp. 19-30.

Garbarino M, Sibona E, Lingua E, et al. (2014) Decline of traditional landscape in a protected area of the southwestern Alps: the fate of enclosed pasture patches in the land mosaic shift. Journal of Mountain Science 11(2): 544-554. DOI: 10.1007/s11629-013-2666-9

Gibon A, Sheeren D, Monteil C, et al. (2010) Modelling and simulating change in reforesting mountain landscapes using a social-ecological framework. Landscape Ecology 25: 267-285.

\section{Electronic Supplementary Material:} Supplementary material (Appendixes 1, 2, 3) is available in the online version of this article at http://dx.doi.org./10.1007/s11629-014-3405-6.

DOI: $10.1007 / \mathrm{s} 10980-009-9438-5$

Giri C, Pengra B, Long J, et al. (2013) Next generation of global land cover characterization, mapping, and monitoring. International Journal of Applied Earth Observation and Geoinformation 25: 30-37. DOI: 10.1016/j.jag.2013.03.005

Grandjean G, Bernardie S, Malet JP, et al. (2013) SAMCO: Society adaptation for coping with mountain risks in a global change context, EGU general Assembly 2013, Apr 2013, Vienne, Austria. 15, pp.EGU2013-7349, 2013. Available online at: https://hal-brgm.archives-ouvertes.fr/hal-00796764/document (Accessed on 12 March 2015)

Houet T, Loveland TR, Hubert-Moy L, et al. (2010) Exploring subtle land use and land cover changes: a framework for future landscape studies. Landscape Ecology 25: 249-266. DOI: $10.1007 /$ s10980-009-9417-x

Houet T, Hubert-Moy L, Tyssot C (2011) Fine scale spatialised prospective modelling - a methodological approach. Application to water management in Brittany. European Journal of Geomatics and Spatial Analysis 21: 67-93. DOI: 10.3166/rig. 21hs.67-93

Houet T, Ribière O, Vacquié L, et al. (2012) Characterizing how Pyrenean landscapes look more and more closed Application in the Haut-Vicdessos valley from the 1940s. SudOuest Européen 33: 41-56. Available online at: http://soe. revues.org/210?lang=en (Accessed on 15 March 2015) (In French)

Houet T, Schaller N, Castets M, et al. (2014) Improving the simulation of fine-resolution landscape changes by coupling top-down and bottom-up land use and cover changes rules. International Journal of Geographical Information Science 28(9): 1848-1876. DOI: $10.1080 / 13658816.2014 .900775$

Houghton RA (2003) Why are estimates of the terrestrial carbon balance so different?. Global Change Biology 9: 50005009. DOI: 10.1046/j.1365-2486.2003.00620.x

IPCC (2000) Special report on emissions scenarios - a special report of working group III of the Intergovernmental Panel on Climate Change. Cambridge University Press, Cambridge, UK.

Klijn JA, Vullings LAE, van de Berg M, et al. (2005) The EURURALIS study: technical document. Available online at: http://www.eururalis.eu/background.htm (Accessed on 10 March 2013)

Lambin EF, Geist HJ (2006) Land-Use and Land-Cover Change - Local processes and Global impacts. Springer-Verlag, Berlin, Germany.

Marohn C, Schreinemachers P, Viet Quang D, et al. (2013) A software coupling approach to assess low-cost soil conservation strategies for highland agriculture in Vietnam. Environmental Modelling and Software 45: 116-128. DOI: 10.1016/j.envsoft.2012.03.020

McGarigal K, Cushman SA, Neel MC, et al. (2002) FRAGSTATS: Spatial pattern analysis program for categorial maps. Computer software program produced by the authors at the University of Massachusetts, Amherst, MA, USA.

MEA (2005) Ecosystem and human well-being: Synthesis. Island Press, Washington DC, USA.

Métailié JP, Paegelow M (2004) Land Abandonment and the Spreading of the Forest in the Eastern French Pyrenees in the Nineteenth to Twentieth Centuries. In: Mazzoleni S, Pasquale di G, Mulligan M, et al. (Eds.) Recent Dynamics of the Mediterranean Vegetation and Landscape. Wiley, Chichester, UK. pp 219-236. 
Mitchley J (2006) Integrated futures for Europe's mountain regions: reconciling biodiversity conservation and human livelihoods. Journal of Mountain Science 3(4): 276-286. DOI: 10.1007/s11629-006-0276-5

Mottet A, Ladet S, Coqué N, et al. (2006) Agricultural land-use change and its drivers in mountain landscapes: a case study in the Pyrenees. Agriculture, Ecosystems and Environment 114(2-4): 296-310. DOI: 10.1016/j.agee.2005.11.017

Prevosto B, Hill D, Coquillard P (2003) Individual-based modelling of Pinus sylvestris after grazing abandonment in the French Massif Central. Plant Ecology 168: 121-137. DOI: 10.1023/A:1024404214782

Price B, Kienast F, Seidl I, et al. (2015) Future landscapes of Switzerland: Risk areas fir urbanization and land abandonment. Applied Geography 57: 32-41. DOI: 10.1016/j. apgeog.2014.12.009

Renwick A, Jansson T, Verburg P, et al. (2013) Policy reform and agricultural land abandonment in the EU. Land Use Policy 30: 446-457. DOI: 10.1016/j.landusepol.2012.005

Rounsevell MDA, Ewert F, Reginster I, et al. (2005) Future scenarios of European agricultural land use: II. Projecting changes in cropland and grassland. Agriculture, Ecosystems and Environment. 107: 101-116. DOI: 10.1016/j.agee.2004. 12.002

Santini M, Valentini R (2011) Predicting hot-spots of land use changes in Italy by ensemble forecasting. Regional Environmental Changes 11: 483-502. DOI: 10.1007/s10113010-0157-x

Sheeren D, Ribiere O, Raynaud B, et al. (2012) Assessing land cover changes in the French Pyrenees since the 1940s: a semiautomatic GEOBIA approach using aerial photographs, Proceedings of the AGILE'2012 conference, 23-27 April 2011, Avignon, France. Available online at: http://w3.geode.univtlse2.fr/permanents/houet/Sheeren_al_100_Poster_ISBN_ AGILE2012.pdf (Accessed March 2015)

Schneeberger N, Buergi M, Hersperger AM, et al. (2007) Driving forces and rates of landscape change as a promising combination for landscape change research - An application on the northern fringe of the Swiss Alps. Land Use Policy 24(2): 349-361. DOI: 10.1016/j.landusepol.2006.04.003

Sleeter BM, Sohl TL, Bouchard M, et al. (2012) Scenarios of land use and land cover change in the conterminous United States: Utilizing the Special Report on Emission Scenarios at Ecoregional Scales. Global Environmental Change 22(4): 896914. DOI: 10.1016/j.gloenvcha.2012.03.008

Sohl TL, Sayler K (2008) Using the FORE-SCE model to project land-cover change in the southeastern United States. Ecological Modelling 219: 9-5. DOI: 10.1016/j.ecolmodel. 2008.08.003

Sohl T, Loveland T, Sleeter B, et al. (2010) Addressing foundational elements of regional land-use change forecasting. Landscape Ecology 25: 233-247. DOI: 10.1007/s10980-0099391-3

Sohl T, Sleeter B, Sayler K, et al. (2012) Spatially explicit landuse and land-cover scenarios for the Great Plains of the United States. Agriculture, Ecosystems and Environment 153: 1-15. DOI: 10.1016/j.agee.2012.02.019

Sohl T, Sayler K, Bouchard M, et al. (2014) Spatially explicit modeling of 1992-210o land cover and forest stand age for the conterminous United States. Ecological Applications 24(5): 1015-1036. doi:10.1890/13-1245.1

Turley MC, Ford ED (2009) Definition and calculation of uncertainty in ecological process models. Ecological Modelling. 220(17): 1968-1983. DOI: 10.1016/j.ecolmodel. 2009.04.046

Turner II BL, Lambin EF, Reenberg A (1995) The emergence of land change science for global environmental change and sustainability. PNAS 104(52): 20666-20671. DOI: 10.1073/ pnas.0704119104

UNEP (2002) Global Environment Outlook 3. United Nation Environmental Program, Nairobi, Kenya

Vacquié L, Houet T, Vigneau C (2013) Characterizing land use and land cover change trajectories. A multiscale approach applied on the Pyrenees mountains. Proceedings of the SAGEO'13 symposium, 23-26 september 2013, Brest, France. pp. 155-167. Available online at: http://sageo2013. sciencesconf.org/conference/sageo2013/pages/SAGEO_2013 actes.pdf (Accessed on 17 March 2015) (In French)

van Meijl H, van Rheenen T, Tabeau A, et al. (2006) The impact of different policy environments on agricultural land use in Europe. Agriculture, Ecosystems and Environment 114(1): 2138 DOI: $10.1016 /$ j.agee.2005.11.006

Veldkamp A, Lambin EF (2001) Predicting land-use change. Agriculture, Ecosystems and Environment 85: 1-6.

Verburg PH., Schot P, Dijst M, et al. (2004) Land use change modelling: current practice and research priorities. Geojournal 61: 309-324. DOI: 10.1007/s10708-004-4946-y

Verburg P, Schulp C, Witte N, et al. (2006a) Downscaling of land use change scenarios to assess the dynamics of European landscapes. Agriculture, Ecosystems and Environment. 114(1): 39-56. DOI: 10.1016/j.agee.2005.11.024

Verburg PH, Rounsevell M, Veldkamp A (2006b) Scenariobased studies of future land use in Europe. Agriculture, Ecosystems and Environment 114(1): 1-6. DOI: 10.1016/j. agee.2005.11.023

Verburg PH, Kok K, Pontius RG, et al. (2006c) Modeling LandUse and Land-Cover Change. In: Lambin EF, Geist HJ (Eds.), Land-Use and Land-Cover Change - Local Processes and Global Impacts, Global Change - The IGBP Series. pp 117-137. Verburg P, van Berkel D, van Doorn A, et al. (2010) Trajectories of land use change in Europe: a model-based exploration of rural futures. Landscape Ecology 25: 217-232. DOI: 10.1007/ s10980-009-9347-7

Vert J, Schaller N, Villien C (2013) Agriculture, Forest, Climate: towards adaptation strategies, Ministry of agriculture and fisheries, Available online at: http://agriculture.gouv.fr/ AFClim-Agriculture-foret-climat (Accessed on 17 June 2011) (In French)

Vert J, Portet F (2010) Prospective study on Agriculture and Energy in 2030. Agriculture adressing energy challenges, Ministry of agriculture and fisheries. Available online at: http://agriculture.gouv.fr/agriculture-energie-2030,1440. (Accessed on 17 March 2015) (In French)

Zimmermann P, Tasser E, Leitinger G, et al. (2010) Effects of land-use and land-cover pattern on landscape-scale biodiversity in the European Alps. Agriculture, Ecosystems and Environment 139: 13-22. DOI: 10.1016/j.agee.2010. 06.010 